GENETIC ASPECTS OF FERTILITY IN CATTLE

\title{
J. PHILIPSSON
}

\section{Department of Animal Breeding and Genetics, Swedish University of Agricultural Saiences S-750 o7 Uppsala/Sweden}

The problem area of female fertility has been discussed, especially as regards its genetic variation and correlations with production, in the light of recently published results. Furthermore the implications in selection of parameters found have been illuminated.

It is concluded that the magnitude of the additive genetic variance in several fertility traits is considerable, despite the generally low heritability values of individual insemination results. The genetic effect of cow culling within herds for poor fertility is almost negligible, while progeny testing bulls for daughter fertility offers valuable information to be used for selection purposes.

Several recent investigations appear to indicate antagonistic relationships between production and fertility. However, the findings are somewhat ambiguous. Though when unfavourable correlations do exist, even though not very strong, detrimental effects on fertility will occur as a consequence of intense long-term selection for yield, if the fertility of daughters is not considered simultaneously with production in selection programmes.

SEIECTION FOR FERTILITY ON THE BASIS OF A.T. DATA

\section{O. SYRSTAD}

Department of Animal Genetics and Breeding Agricultural University of Norway, 1432 As-NLH/Norway

I. Conception rate and calving interval are determined by the fertility of the bull and the fertility of the cow jointly. One unit of genetic improvement in male fertility is therefore of equal importance to one unit of improvement in female fertility.

2. The heritability of bull fertility, as measured by the N.R.-rates from a few hundred inseminations, is large enough to provide a basis for efficient selection. The genetic standard deviation is, however, considerably less for male than for female fertility.

3. The genetic correlation between male and female fertility is slight, and the same holds true for the genetic correlation between male fertility and milk production.

4. In the final selection of progeny tested bulls due attention should be given to the estimated breeding value of the bull with respect to male fertility.

GENETIC INFERENCES FROM THE FREQUENCY DISTRIBUTION OF RETURN INTERVAIS IN DAIRY COWS

\section{R. BAR-ANAN}

\section{The Institute of Animal Science, The Volcani Research Center Bet Dagan/Israel}

Several investigations have pointed out that cycles between inseminations are longer by about two days than cycles between estri. These differences are in concord with slaughterhouse findings of very early embryonic death, which may postpone the recurrent estrus very slightly or not at all. The main difference between regular breeding cows and repeat breeder cows was not in fertilization but in the survival of the zygote above one week.

Heritability values for implantation failure, estimated by the skewness of return intervals within 3I days were zero for the effect of the mating sire and about 0.1 by the sire of the cow.

Low fertile bulls had high proportions of regularly returning mates and low fertile daughtergroups had skewed return intervals.

Heritability estimates for abortions post pregnancy tests were very low. The hypothesis was advanced of additive genetic variation among males in fertilization and among females in implantation and of non-additive mutations in the embryo. 